J. Brimacombe MB CHB FRCA MD, C. Keller MD, *

\section{Successful pharyngeal pulse oximetry in low perfusion states}

Purpose: We describe pharyngeal oximetry with the laryngeal mask airway in two patients with low perfusion states where finger oximetry failed.

Clinical Features: One patient was a 47-yr-old man with septic shock and the other a 64-yr-old man with multiorgan failure. In both patients, a \# 4 laryngeal mask airway with a pediatric pulse oximeter probe was inserted behind the tracheal tube. A good waveform was obtained and oxygen saturation was 0-2\% lower than arterial samples.

Conclusion: Pharyngeal oximetry with the laryngeal mask airway is feasible in low perfusion states when finger oximetry fails.

Objectif : Décrire l'oxymétrie pharyngienne utilisant le masque laryngé pour deux patients qui présentaient un lent débit circulatoire et chez qui l'oxymétrie digitale avait échoué.

Éléments cliniques : Le premier patient avait 47 ans et souffrait de choc septique; le second, âgé de 64 ans, présentait une défaillance multiorganique. Dans les deux cas, on a inséré un masque laryngé $n^{\circ} 4$ et une sonde pédiatrique d'oxymétrie pulsée derrière le tube trachéal. Une onde bien formée a été obtenue et la saturation en oxygène était de $0-2 \%$ plus basse que celle des échantillons artériels.

Conclusion : L'oxymétrie pharyngienne réalisée avec le masque laryngée est faisable dans des cas de faible débit sanguin, lorsque l'oxymétrie digitale est impossible.

From the University of Queensland, Department of Anaesthesia and Intensive Care, Cairns Base Hospital, Australia.

*Present address: Department of Anaesthesia and Intensive Care Medicine, Leopold-Franzens University, 6020, Innsbruck, Austria. Address correspondence to: Dr. J. Brimacombe. Phone: 61-7-40-506960; Fax: 61-7-40-506854; E-mail: 100236,2343@compuserve.com Accepted for publication June 12, 2000. 
$\mathrm{F}$

INGER oximetry may be inadequate in low perfusion states and several alternative locations for the oximeter probe have been described including the cheek, ${ }^{1}$ nose ${ }^{2}$ and tongue. ${ }^{3}$ We recently showed that pharyngeal oximetry with the laryngeal mask airway (LMA) is feasible and more accurate than finger oximetry in hemodynamically stable, well-oxygenated anesthetised patients provided the LMA cuff is at least partially inflated. ${ }^{4}$ The following cases illustrate that pharyngeal oximetry with the LMA is also feasible in low perfusion states when finger oximetry fails.

\section{Case \#1}

A 47-yr-old, $60 \mathrm{~kg}$ man with septic shock presented for urgent laparotomy. Before anesthesia induction, the mean blood pressure was $50 \mathrm{~mm} \mathrm{Hg}$ despite inotropic support and fluid resuscitation. Arterial blood gas analysis from the femoral artery showed an oxygen saturation $\left(\mathrm{SaO}_{2}\right)$ of $100 \%$ while breathing $6 \mathrm{~L}$ oxygen via a Hudson mask. Once the trachea was intubated, an attempt at obtaining pulse oximetry readings from the cheek, ears and tongue failed. A size \#4 LMA with a pediatric pulse oximeter probe (Datex Medical Instrumentation, Helsinki, Finland) attached to the backplate (Figures 1,2) was inserted behind the tracheal tube and the cuff inflated with $20 \mathrm{ml}$ air. A clear waveform was obtained with an $\mathrm{SpO}_{2}$ of 99$100 \%$ breathing oxygen $100 \%$. During the procedure, which lasted an hour, the mean blood pressure remained at $40-50 \mathrm{~mm} \mathrm{Hg}$. The pharyngeal oximeter continued to provide a good waveform with $\mathrm{SpO}_{2}$ values $0-1 \%$ lower than $\mathrm{SaO}_{2}$ from three samples taken from the femoral arterial line at $15 \mathrm{~min}$ intervals $\left(\mathrm{SpO}_{2}\right.$ vs $\mathrm{SaO}_{2}: 99 \%$ vs $100 \% ; 100 \%$ vs $100 \% ; 100 \%$ vs $100 \%)$. The hematocrit during these measurements was 0.46 . Heart rate from the pharyngeal oximeter was similar to the electrocardiograph $( \pm 2$ beats per minute). There was deterioration in the pharyngeal oximetry waveform when the patient was transferred to the intensive care unit. The device was removed and the light emitter and sensor were found to be covered with a thick layer of secretions. The signal improved once the secretions were removed and the LMA reinserted. The total time the LMA was in situ was three hours. No blood was noted on the LMA when it was removed.

\section{Case \#2}

A 64-yr-old, $87 \mathrm{~kg}$ man was in the intensive care unit with multiorgan failure following a motor vehicle accident. He had a mean blood pressure of 35-50 $\mathrm{mm} \mathrm{Hg}$ and $\mathrm{SaO}_{2}$ of $83-85 \%$ while breathing oxygen $100 \%$

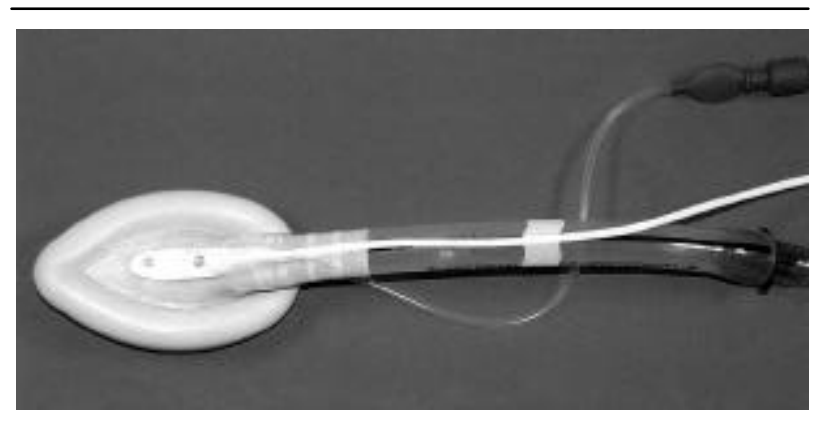

$\overline{\text { FIGURE } 1 \text { Pulse oximeter attached to the laryngeal mask airway }}$ with an adhesive dressing that does not cover the optical components.

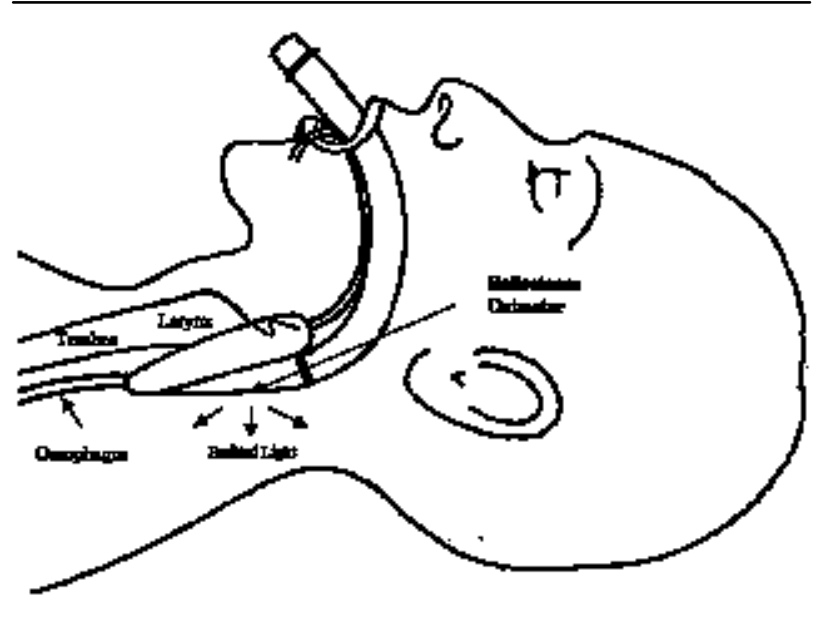

FIGURE 2 Schematic diagram of laryngeal mask airway in pharynx indicating the location of the pharyngeal oximeter.

despite maximal cardiovascular and respiratory support. Finger oximetry had become increasingly difficult with a poor waveform and inaccurate readings when compared with the directly measured values. A digital nerve block ${ }^{5}$ had failed to improve the readings. Transient readings were obtained from the cheek, but this failed as the patient's condition worsened. A size \#4 LMA with oximetry probe was inserted behind the tracheal tube and the cuff inflated with $20 \mathrm{ml}$ air. A clear waveform was obtained. The $\mathrm{SpO}_{2}$ was $85-88 \%$ and was $0-2 \%$ lower than the $\mathrm{SaO}_{2}$ from four samples taken from the radial arterial line at 15 min intervals $\left(\mathrm{SpO}_{2}\right.$ vs $\mathrm{SaO}_{2}: 85 \%$ vs $86 \% ; 85 \%$ vs $87 \%$; $88 \%$ vs $88 \% ; 87 \%$ vs $89 \%)$. The hematocrit during these measurements was 0.39. Heart rate from the pharyngeal oximeter was identical to the electrocardiograph. 
The pharyngeal oximetry probe continued to provide a good waveform and accurate readings even when the blood pressure was less than $35 \mathrm{~mm} \mathrm{Hg}$. The total time the LMA was in situ was five hours. No blood was noted on the LMA when it was removed.

\section{Discussion}

These cases illustrate that pharyngeal oximetry is possible in low perfusion states when oximetry from the fingers, ear, tongue and cheek fails. In our recent study ${ }^{4}$ all patients were hemodynamically stable and pharyngeal $\mathrm{SpO}_{2}$ was $<0.7 \%$ lower than $\mathrm{SaO}_{2}$. In the current cases, $\mathrm{SpO}_{2}$ was only $0-2 \%$ lower than $\mathrm{SaO}_{2}$ despite global hypoperfusion. The pharynx is a highly perfused structure and is in close proximity to the carotid artery. We speculate that some of the emitted light from the oximeter may be reflected off the opaque surfaces of the vertebral bodies and back into the plane of the pharyngeal mucosa via the carotid artery. In low perfusion states, carotid blood flow is preserved to allow blood flow to the brain. This may explain why an oximetry trace was obtained, even when the blood pressure was $\leq 35 \mathrm{~mm} \mathrm{Hg}$. In our recent study, ${ }^{4}$ patients had $\mathrm{SpO}_{2}>98 \%$, but in case \#2 $\mathrm{SpO}_{2}$ was $<90 \%$. This suggests that pharyngeal oximetry can provide accurate readings in hypoxemic states. Our data compares favourably with finger oximetry that is usually accurate to $2 \pm 1 \%$ of $\mathrm{SaO}_{2}$ over the range $70-100 \%{ }^{6}$ Lindberg et al. ${ }^{7}$ have reviewed the principles and clinical implications of pulse oximetry.

The LMA was left in situ for three to five hours without apparent mucosal trauma, but no formal assessment of mucosal injury was made. In our recent study of 20 anesthetised patients, there were no complaints of postoperative sore throat. ${ }^{4}$ The LMA exerts pressures that are usually much lower than pharyngeal perfusion pressure, ${ }^{8,9}$ but pharyngeal perfusion pressure may be lower in hypoperfusion states. The LMA has been used in intensive care patients for up to $24 \mathrm{hr}$ without pharyngeal trauma being noted.10,11 Further studies are required to determine the maximum duration that the LMA may be safely left in situ for the purposes of pharyngeal oximetry. Other pharyngeal airways, such as the cuffed oropharyngeal airway, ${ }^{12}$ may also facilitate pharyngeal oximetry and cause less trauma.

Finally, in case \#1, there was a loss of signal from the pharyngeal oximeter due to thick secretions. Prior to insertion of the LMA we failed to suction out the patient's pharynx. We would suggest suctioning the pharynx prior to insertion of the LMA to optimise the signal. Similarly, if the waveform deteriorates, the LMA should be removed and pharyngeal suctioning performed.
We conclude that pharyngeal oximetry with the LMA is feasible in low perfusion states when finger oximetry fails.

\section{References}

1 O'Leary RJ Jr, Landon M, Benumof JL. Buccal pulse oximeter is more accurate than finger pulse oximeter in measuring oxygen saturation. Anesth Analg 1992; 75 : 495-8.

2 Ezri T, Lurie S, Konichezky S, Soroker D Pulse oximetry from the nasal septum. J Clin Anesth 1991; 3: 447-50.

3 Jobes DR, Nicolson SC. Monitoring of arterial hemoglobin oxygen saturation using a tongue sensor. Anesth Analg 1988; 67: 186-8.

4 Keller C, Brimacombe J, Agrò F, Margreiter J. A pilot study of pharyngeal pulse oximetry with the laryngeal mask airway: a comparison with finger oximetry and arterial saturation measurements in healthy anesthetized patients. Anesth Analg 2000; 90: 440-4.

5 Bourke DL, Grayson RF. Digital nerve blocks can restore pulse oximeter signal detection. Anesth Analg 1991; 73: 815-7.

6 Jensen LA, Onyskiw JE, Prasad NGN. Meta-analysis of arterial oxygen saturation monitoring by pulse oximetry in adults. Heart Lung 1998; 27: 387-408.

7 Lindberg LG, Lennmarken C, Vegfors M. Pulse oximetry - clinical implications and recent technical developments. Acta Anaesthesiol Scand 1995; 39: 279-87.

8 Brimacombe J, Keller C A comparison of pharyngeal mucosal pressure and airway sealing pressure with the laryngeal mask airway in anesthetized adult patients. Anesth Analg 1998; 87: 1379-82.

9 Brimacombe J, Keller C, Pübringer F. Pharyngeal mucosal pressure and perfusion. A fiberoptic evaluation of the posterior pharynx in anesthetized adult patients with a modified cuffed oropharyngeal airway. Anesthesiology 1999; 91: 1661-5.

10 Arosio EM, Conci F. Use of the laryngeal mask airway for respiratory distress in the intensive care unit. Anaesthesia 1995; 50: 635-6.

11 Taylor JC, Bell GT. An asthmatic weaned from a ventilator using a laryngeal mask. Anaesthesia 1995; 50: 454-5.

12 Brimacombe JR, Brimacombe JC, Berry A, et al. A comparison of the laryngeal mask airway and cuffed oropharyngeal airway in anesthetized adult patients. Anesth Analg 1998; 87: 147-52. 